\title{
Lymphadenectomy Specimens in a Large Retrospective Cohort of Pediatric Patients Reveal No in situ Lymphomas but a Broad Spectrum of Reactive Changes
}

\author{
Yara Banz $^{\mathrm{a}} \quad$ Alexandar Tzankov $^{\mathrm{b}}$ Stephan Dirnhofer ${ }^{\mathrm{b}} \quad$ Aurel Perren $^{\mathrm{a}}$ \\ Sylvia Hoeller ${ }^{b}$ \\ anstitute of Pathology, University of Bern, Bern, and ${ }^{\mathrm{b}}$ Institute of Pathology, University Hospital, Basel, Switzerland
}

\section{Key Words}

Follicular lymphoma . Mantle cell lymphoma .

Immunodeficiency

\section{Abstract}

Objectives: While the incidence and prevalence of in situ follicular neoplasia (ISFN) and in situ mantle cell neoplasia (ISMCN) in adults are well documented, little is known about these early (precursor) lesions in pediatric populations. The aim of this study was to analyze so-called 'reactive' lymph nodes harvested for the purpose of staging solid tumors, unexplained lymphadenopathies, or presumed inflammatory processes or in conjunction with other surgical interventions in children and adolescents aged $<18$ years, with special attention to ISFN and ISMCN. Methods: Formalin-fixed, paraffin-embedded reactive lymph node samples from an unselected pediatric population from two catchment areas in Switzerland were retrospectively analyzed for the presence of ISFN and ISMCN and specific reactive lymph node patterns. Results: While a diverse range of histopathological patterns of reactive lymph node changes with a particular periodic increase in mycobacterioses could be observed in this pediatric population, not a single case of ISFN or ISMCN was found. Conclusions: Early histological lymphomagenesis equivalents in the form of in situ lymphomas are exceedingly rare

\section{KARGER}

(C) 2016 S. Karger AG, Basel

E-Mail karger@karger.com

www.karger.com/pat events in children and young adolescents. The spectrum of reactive lymph node changes is large, with differences possibly determined by regional variations in geography, demographics, catchment areas, seasons, and years, respectively.

(c) 2016 S. Karger AG, Basel

\section{Introduction}

As with many cancers, lymphomagenesis has been recognized as a multistep process with the acquisition of a range of oncogenic events usually requiring many years or decades to evolve. More recently, early lesions in lymphomagenesis have been described, including in particular certain variants of follicular lymphoma such as in situ follicular neoplasia (ISFN) [1], previously known as follicular lymphoma in situ [2], in which the nodal architecture is preserved and the lesion can by definition only be detected by immunohistochemistry (IHC), partial involvement by follicular lymphoma, and duodenal follicular lymphoma, as well as in situ mantle cell neoplasia (ISMCN), previously known as in situ mantle cell lymphoma [3-6].

The $t(14 ; 18)(q 32 ; q 21)$ translocation, which results from erroneous $V D J$ recombination, is one of the earliest events in follicular lymphomagenesis, occurring in B-cell

Yara Banz

Institute of Pathology, University of Bern

Murtenstrasse 31

CH-3010 Bern (Switzerland)

E-Mail yara.banz@pathology.unibe.ch 
precursors in the bone marrow [7]. Of note, this has also been observed in very low frequencies in circulating $B$ cells from healthy adults $[8,9]$, increasing in frequency in older individuals [10]. This genetic aberration, which is found in the vast majority of follicular lymphomas [11], leads to constitutive pathologic overexpression of the anti-apoptotic bcl-2 protein in germinal center B cells [12], readily detectable in tissue sections by IHC.

Similar to ISFN, the nodal architecture in ISMCN is preserved and can only be recognized by IHC detecting cyclin D1 expression on B cells in the mantle zones $[5,6]$. These ISMCN carry the characteristic $t(11 ; 14)$ translocation observed in full-blown mantle cell lymphoma [13]. Furthermore, cells carrying the $t(11 ; 14)$ translocation can also be detected in the peripheral blood of healthy individuals, albeit at a very low frequency [14]. In ISFN as well as in ISMCN, detection of transformed B cells within morphologically intact follicles may represent the tissue counterpart of transformed/translocation-carrying lymphocytes in the circulation.

The incidence and prevalence of ISFN in the adult population have been described and they appear to be low [15-17]. Similarly, ISMCN is an exceptionally rare event, as described by Adam et al. [18]. Although it is to be expected that ISFN and ISMCN are a very rare event in the pediatric population, this has not been studied systematically before. The primary aim of this study therefore was to examine the frequency of nodal in situ neoplasms of the ISFN type, as well as ISMCN, in an unselected pediatric population by retrospective analysis of surgical lymph node specimens. In light of the detailed reviews necessary to rule out (incidental) in situ neoplasms, the secondary aim was to more closely categorize the reactive lymph node changes observed.

\section{Materials and Methods}

\section{Case Selection}

Cases for retrospective analysis were selected from pediatric patients with lymphadenectomy specimens from the Institutes of Pathology of the University of Bern and the University Hospital of Basel between 1990 and 2013. A search was conducted in both institutes using the software PathoWin+ (Basys Data, Binningen, Switzerland) with the terms 'lymphadenectomy'/'lymph node'. Lymph nodes had been removed for the purpose of staging solid tumors, unexplained lymphadenopathies or lymph node enlargement, or presumed inflammatory processes, or in conjunction with other surgical interventions (e.g. appendectomy). This study was approved by the ethics committee.

Formalin-fixed, paraffin-embedded samples were available from all patients. Inclusion criteria included: absence of overt lymphoma in the examined lymph nodes, a negative clinical history of lymphoma, and presence of at least one reactive follicle with a recognizable germinal center in the routine hematoxylin and eosin (H\&E)-stained sections. All patients were 18 years or younger at the time of lymph node excision. The main primary exclusion criteria were: age $>18$ years, a history of lymphoma, and poor material quality or quantity (inadequate initial resection material or insufficient remaining tissue volume or tissue preservation). A total of 392 patients (234 males and 158 females, median age 9.0 years, range $0.2-18$ years) were identified and amenable for analysis.

\section{Immunohistochemistry}

All lymph nodes had been stained for routine histological examination with H\&E. Those slides were used for double-headed review of the diagnoses (Y.B. and A.T. or S.H. and A.T.). All cases were stained for bcl-2 as well as for cyclin D1 by IHC on an automated immunostainer (Leica BOND-III, Leica Biosystems, Nussloch, Germany, in Bern or BenchMark XT, Ventana Medical Systems, Tucson, Ariz., USA, in Basel). Following pretreatment according to the manufacturer's protocols, the slides were incubated at room temperature with monoclonal mouse anti-human bcl-2 (working concentration 1:100; Dako, Agilent Technologies, Glostrup, Denmark) and cyclin D1 (working concentration 1:25; Cell Marque, Rocklin, Calif., USA). Antigen detection was performed using a commercial detection kit (Bond Polymer Refine Detection, UltraView Detection Kit; Ventana) with diaminobenzidin as the chromogen.

\section{Analysis of HÆE Sections and IHC Staining}

All H\&E sections were reviewed by at least 2 board certified pathologists and assessed for suitability (see above). A morphological pattern diagnosis was made according to the following categories: follicular hyperplasia, paracortical hyperplasia, sinus histiocytosis, necrotizing and nonnecrotizing granulomatous lymphadenitis, suppurative lymphadenitis, and (other, nonspecific) reactive changes. One to 4 histological diagnoses were made in each individual case. For assessment of the expression profile of bcl-2 and cyclin D1, the stained slides were evaluated by experienced hematopathologists and ambiguous cases discussed.

The diagnostic criteria for ISFN have previously been described $[4,18]$. They encompass lymph nodes with an intact lymphoid architecture, including the presence of preserved paracortical/interfollicular areas and follicles with intact mantle zones. bcl-2-positive neoplastic cells of mainly the centrocytic type are confined to the germinal centers of the follicles, which show a low proliferative index. This definition aims to separate ISFN from partial involvement by follicular lymphoma, in which an altered architecture with larger, often grouped affected follicles is observed with illdefined mantle cuffs, the presence of centroblasts, and a variable intensity of bcl-2 staining. Similar to ISFN, the nodal architecture in ISMCN is preserved, and as such it can also be recognized by IHC staining as the presence of cyclin D1-expressing cells within the mantle zone of otherwise reactive follicles $[5,6]$.

\section{Statistical Analysis}

Results between groups were compared using a one-way-analysis of variance (ANOVA). $\mathrm{p}<0.05$ was considered statistically significant. Analyses were conducted using SAS v9.2 (SAS Institute, Cary, N.C., USA). 
Table 1. General characteristics of the pediatric cohorts from Bern and Basel

\begin{tabular}{lllll}
\hline & $\begin{array}{l}\text { Bern } \\
\text { cohort }\end{array}$ & $\begin{array}{l}\text { Basel } \\
\text { cohort }\end{array}$ & Total & p value \\
\hline $\begin{array}{l}\text { Sex, } n(\%) \\
\text { Male }\end{array}$ & $194(61.6)$ & $40(51.9)$ & $234(59.7)$ & n.s. \\
Female & $121(38.4)$ & $37(48.1)$ & $158(40.3)$ & \\
\hline $\begin{array}{l}\text { Age, years } \\
\text { Total }\end{array}$ & & & & \\
$\quad \begin{array}{l}\text { Mean } \pm \text { SD } \\
\quad \text { Median }\end{array}$ & $9.6 \pm 5.8$ & $9.1 \pm 5.3$ & $9.5 \pm 5.7$ & n.s. \\
$\quad$ Range & $0.0-18$ & 0.0 & 9.0 & \\
$\begin{array}{l}\text { Male } \\
\quad \text { Mean } \pm \text { SD }\end{array}$ & $9.8 \pm 5.8$ & $9.9 \pm 5.3$ & $9.5 \pm 5.7$ & \\
$\quad \begin{array}{l}\text { Median } \\
\text { Range }\end{array}$ & 9.0 & 9.5 & 10.0 & \\
Female & & & $0.25-18$ & \\
$\quad \begin{array}{l}\text { Mean } \pm \text { SD } \\
\text { Median }\end{array}$ & $9.8 \pm 5.8$ & $8.3 \pm 5.0$ & $9.5 \pm 5.7$ & n.s. \\
$\quad$ Range & 10.0 & 7.0 & 9.0 & \\
\hline
\end{tabular}

n.s. $=$ Not significant

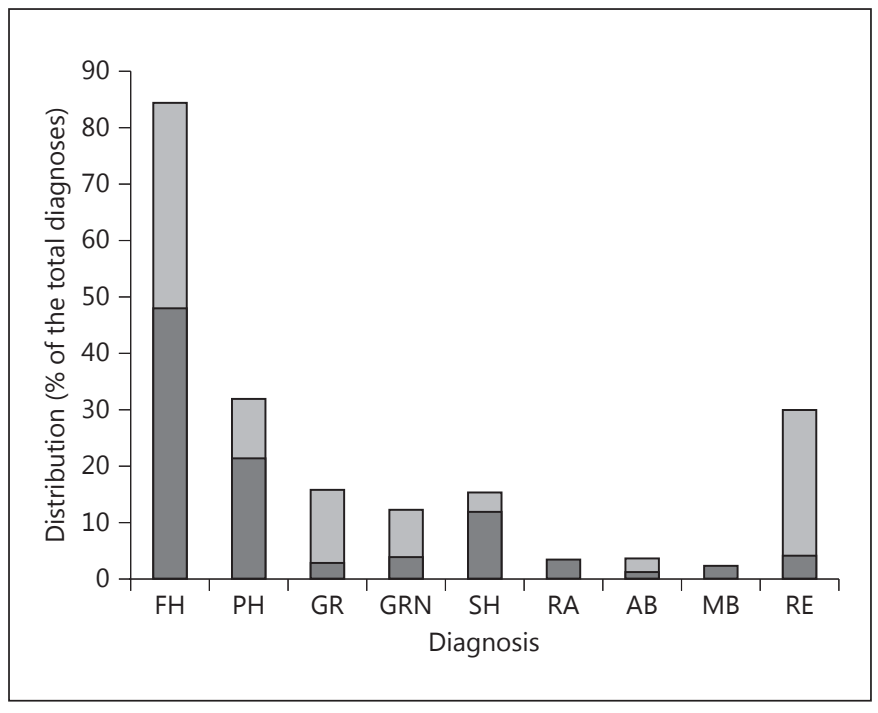

Fig. 1. Distribution of the diagnoses from the Basel cohort (light grey) and the Bern cohort (dark grey) as percentages of the total diagnoses made in the surgical lymphonodectomy specimens. $\mathrm{FH}=$ Follicular hyperplasia; $\mathrm{PH}=$ paracortical hyperplasia; $\mathrm{GR}=$ granulomatous lymphadenitis; GRN = granulomatous lymphadenitis with necrosis; $\mathrm{SH}=$ sinus histiocytosis; $\mathrm{RA}=$ reticulohistiocytic lymphadenitis with abscess; $\mathrm{AB}=$ frank abscess; $\mathrm{RE}=$ reactive (not otherwise categorized, including Kikuchi lymphadenitis, Rosai-Dorfman lymphadenits, lymphangiectasia and fibrosis).

10.6\%). Granulomatous lymphadenitis, with or without necrosis, constituted $9.2 \%(n=49)$ of all of the diagnoses in the entire group, being particularly strongly represented in the Basel cohort, where this diagnosis constituted $21.2 \%$ of all diagnoses. No sex predilection or annual or seasonal peak was observed. While in most cases a descriptive diagnosis based on the morphological presentation was made, some lymphonodectomy specimens yielded a definite diagnosis, in particular also after additional analyses (including molecular pathology; see table 2).

\section{Results of IHC Staining}

In all tissue sections of the entire cohort examined by conventional histology and IHC, not a single case of ISFN or ISMCN was detected. Clinical follow-up, where available, revealed development of lymphoma in 1 case from Basel with a diagnosis of nodular lymphocyte-predominant Hodgkin lymphoma 1 year after the initial lymph node excision in a 15-year-old boy. In 2 cases from Bern, EBV-associated lymphomas (diffuse large B-cell and Hodgkin's lymphoma, classical type) were diagnosed in 2 brothers aged 5 and 16 years (data last reviewed at the end of 2015). 
Table 2. Distribution of infectious and immune-dysregulatory lymphadenopathies

\begin{tabular}{ll}
\hline Diagnosis & Basel/Bern (total) \\
\hline Atypical mycobacteriosis & $1 / 1(2)$ \\
Mycobacterium avium LA & $2 / 1(3)$ \\
Mycobacterium tuberculosis LA & $3 / 2(5)$ \\
Bartonella henselae (cat scratch) LA & $1 / 5(6)$ \\
Rosai-Dorfman LA & $1 / 0(1)$ \\
Retrovirus-associated LA ${ }^{1}$ & $3 / 0(3)$ \\
Immune-dysregulatory LA & $2 / 3(5)$ \\
\hline
\end{tabular}

${ }^{1}$ One confirmed HIV+ case and 2 cases highly suspicious for HIV based on the morphological presentation but without conclusive follow-up data. ${ }^{2}$ One case of DiGeorge syndrome (Basel) and 4 presumed cases of autoimmune lymphoproliferative syndrome ( 1 in Basel and 3 in Bern). LA = Lymphadenopathy.

\section{Discussion}

While the frequency of (incidental) ISFN and ISMCN in adults has been described [15-18], and its prevalence in the pediatric population is indeed expected to be even lower, no systematic study exists to prove the point of the true prevalence of (incidental) early nodal neoplasms, comprising ISFN and ISMCN, in an unselected pediatric population and to describe the morphological patterns of the reactive changes observed.

In this large pediatric population (1990-2013), not a single case of ISFN or ISMCN lymphoma was detected.

In previous studies of adult populations, the prevalence of ISFN has been shown to be in the low percentages [15-17], whereas the prevalence of the signature $t(14 ; 18)$ translocation in the peripheral blood of healthy individuals is comparatively high, increasing with age [8$10,19]$. While cord blood samples and peripheral blood mononuclear cells from children aged $<10$ years did not show any positive cells using quantitative real-time polymerase chain reaction [16], this increased to $66 \%$ of individuals in their 5th decade. Compared to ISFN, the prevalence of ISMCN in the adult population is even lower [18]. The prevalence and incidence of follicular lymphoma and particularly mantle cell lymphoma in the pediatric population are much lower compared to values in adults [20]. As current evidence suggests that ISFN and ISMCN are early lesions in lymphomagenesis, preceding the occurrence of full-blown lymphoma by years if not decades, it is expected, but has to date not been proven in a large study, that such lesions will occur with a much lower frequency in a pediatric population. Indeed, ISFN and ISMCN were not detected in this large unselected pediatric population. The probability of the appearance of the $t(14 ; 18)$ translocation, which, on the whole, appears to be the only chromosomal imbalance (detectable by array CGH) in follicular lymphoma in situ [21], is likely to increase with time and adequately explains the lack of ISFN detected in this young age group. Furthermore, although smoking and exposure to pesticides cannot be entirely excluded, the factors predisposing to increased levels of circulating $t(14 ; 18)$ cells [21-23] are unlikely to have been significantly present in this study population.

Of note, this study did not specifically look at potential precursor lesions for the now clearly recognized pediatric type follicular lymphoma, an indolent type of follicular lymphoma mainly affecting children and young adults, notably lacking the classical $t(14 ; 18)$ translocation and bcl-2 protein expression [24].

In addition to providing insight into the presence - or in this case the absence - of in situ lymphocytic neoplasias in a pediatric population, our study also provides interesting information on the distribution of reactive lymph node changes in lymphadenectomy specimens. The spectrum of reactive lymph node changes was broad, with heterogeneous distributions possibly determined by regional variations in geography, demographics, catchment area, season, and year, respectively. As such, in pediatric lymph node samples lacking overt infiltration by malignant lymphoma, the results of the current study support the necessity for a detailed workup to exclude treatable infectious or inflammatory alterations responsible for the observed reactive changes and to 'exempt' the pathologist from undertaking extensive studies to exclude the unlikely event of ISFN or ISMCN. Interestingly, in a longer follow-up, 1 patient was diagnosed with DiGeorge syndrome and 4 with autoimmune lymphoproliferative syndrome, 2 siblings of whom developed B-cell lymphoproliferations during the course of the follow-up. Also in these select cases, however, no early in situ lesions were observed.

\section{Study Limitations}

Although the children undergoing lymphadenectomy, per definition, do not constitute an entirely 'healthy' population as such, there is no reason to believe that they differ significantly in their risk of presenting with ISFN or ISMCN compared to a truly healthy pediatric cohort. Furthermore, although extensive follow-up was not routinely available, only 3 cases presented with a malignant (non-mantle cell lymphoma and non-follicular lymphoma) lymphoma over time. 
In summary, in situ neoplasia of the ISFN and ISMCN type before the age of 18 years is an exceedingly rare and likely clinically insignificant finding. So, while this study provides an expected 'negative result', proof of this is of imminent importance as it provides first-hand evidence for the hypothesis of stepwise lymphomagenesis with age. Importantly, our data suggests that ancillary studies in addition to routine stains are not warranted to specifically search for and rule out ISFN or ISMCN. Clinically relevant nonneoplastic lymph node changes, in particular those of an infectious or immune-dysregulatory nature, are much more important to recognize to potentially guide clinical management and determine the future follow-up of pediatric patients with lymphadenopathies.

\section{Acknowledgements}

The authors would like to thank Markus Baenziger and his team (Histopathology, Bern) and Prof. Inti Zlobec and her team (Translational Research Unit, Bern), as well as the histopathology team in Basel for their excellent technical support.

\section{References}

1 Swerdlow S, Campo E, Pileri S, Harris N, Stein H, Siebert R, Advani R, Ghielmini M, Salles G, Zelenetz A, Jaffe E: The 2016 revision of the World Health Organization classification of lymphoid neoplasms. Blood 2016;127:23752390.

2 Swerdlow S, Campo E, Harris N, Jaffe E, Pileri S, Stein H, Thiele J, Vardiman J: WHO Classification of Tumours of Haematopoietic and Lymphoid Tissues. Geneva, WHO, 2008.

3 Schmatz AI, Streubel B, Kretschmer-Chott E, Püspök A, Jäger U, Mannhalter C, Tiemann M, Ott G, Fischbach W, Herzog P, Seitz G, Stolte M, Raderer M, Chott A: Primary follicular lymphoma of the duodenum is a distinct mucosal/submucosal variant of follicular lymphoma: a retrospective study of 63 cases. J Clin Oncol 2011;29:1145-1151.

4 Cong P, Raffeld M, Teruya-Feldstein J, Sorbara L, Pittaluga S, Jaffe ES: In situ localization of follicular lymphoma: description and analysis by laser capture microdissection. Blood 2002;99:3376-3382.

5 Nodit L, Bahler DW, Jacobs SA, Locker J, Swerdlow SH: Indolent mantle cell lymphoma with nodal involvement and mutated immunoglobulin heavy chain genes. Hum Pathol 2003;34:1030-1034.

6 Bassarova A, Tierens A, Lauritzsen GF, Fossa A, Delabie J: Mantle cell lymphoma with partial involvement of the mantle zone: an early infiltration pattern of mantle cell lymphoma? Virchows Arch 2008;453:407-411.

7 Tsujimoto Y, Gorham J, Cossman J, Jaffe E, Croce CM: The $t(14 ; 18)$ chromosome translocations involved in B-cell neoplasms result from mistakes in VDJ joining. Science 1985; 229:1390-1393.

8 Limpens J, Stad R, Vos C, de Vlaam C, de Jong D, van Ommen GJ, Schuuring E, Kluin PM: Lymphoma-associated translocation $\mathrm{t}(14 ; 18)$ in blood B cells of normal individuals. Blood 1995;85:2528-2536.
9 Dolken G, Illerhaus G, Hirt C, Mertelsmann $\mathrm{R}: \mathrm{BCL}-2 / \mathrm{JH}$ rearrangements in circulating $\mathrm{B}$ cells of healthy blood donors and patients with nonmalignant diseases. J Clin Oncol 1996;14:1333-1344.

10 Liu Y, Hernandez AM, Shibata D, Cortopassi GA: BCL2 translocation frequency rises with age in humans. Proc Natl Acad Sci USA 1994; 91:8910-8914.

11 Horsman DE, Gascoyne RD, Coupland RW, Coldman AJ, Adomat SA: Comparison of cytogenetic analysis, southern analysis, and polymerase chain reaction for the detection of $\mathrm{t}(14 ; 18)$ in follicular lymphoma. Am J Clin Pathol 1995;103:472-478.

12 Hockenbery D, Nuñez G, Milliman C, Schreiber RD, Korsmeyer SJ: Bcl-2 is an inner mitochondrial membrane protein that blocks programmed cell death. Nature 1990;348:334336.

13 Aqel N, Barker F, Patel K, Naresh KN: In-situ mantle cell lymphoma - a report of two cases. Histopathology 2008;52:256-260.

14 Hirt C, Schuler F, Dolken L, Schmidt CA, Dolken G: Low prevalence of circulating $\mathrm{t}(11$; 14)(q13;q32)-positive cells in the peripheral blood of healthy individuals as detected by real-time quantitative PCR. Blood 2004;104: 904-905.

15 Henopp T, Quintanilla-Martínez L, Fend F, Adam P: Prevalence of follicular lymphoma in situ in consecutively analysed reactive lymph nodes. Histopathology 2011;59:139142.

16 Montes-Moreno S, Castro Y, Rodríguez-Pinilla SM, García JF, Mollejo M, Castillo ME, Bas-Vernal A, Barrionuevo-Cornejo C, Sanchez-Verde L, Menarguez J, Cigudosa JC, Piris MA: Intrafollicular neoplasia/in situ follicular lymphoma: review of a series of 13 cases. Histopathology 2010;56:658-662.

17 Bermudez G, Gonzalez de Villambrosia S, Martinez-Lopez A, Batlle A, Revert-Arce J, Cereceda Company L, Ortega Bezanilla, C, Piris M,
Montes-Moreno S: Incidental and Isolated Follicular Lymphoma In Situ and Mantle Cell Lymphoma In Situ Lack Clinical Significance. Am J Surg Pathol 2016;40:943-949.

18 Adam P, Schiefer AI, Prill S, Henopp T, Quintanilla-Martínez L, Bösmüller HC, Chott A, Fend F: Incidence of preclinical manifestations of mantle cell lymphoma and mantle cell lymphoma in situ in reactive lymphoid tissues. Mod Pathol 2012;25:1629-1636.

19 Dölken G, Dölken L, Hirt C, Fusch C, Rabkin CS, Schüler F: Age-dependent prevalence and frequency of circulating $t(14 ; 18)$-positive cells in the peripheral blood of healthy individuals. J Natl Cancer Inst Monogr 2008;39: 44-47.

20 van Leeuwen MT, Turner JJ, Joske DJ, Falster MO, Srasuebkul P, Meagher NS, Grulich AE, Giles GG, Vajdic CM: Lymphoid neoplasm incidence by WHO subtype in Australia 1982-2006. Int J Cancer 2014;135:2146-2156.

21 Schmidt I, Salaverria I, Haake A, Bonzheim I, AdamP, Montes-Moreno S, Piris MA, Fend F, Siebert R, Quintanilla-Martinez L: Increasing genomic and epigenomic complexity in the clonal evolution from in situ to manifest $\mathrm{t}(14$ 18)-positive follicular lymphoma. Leukemia 2014;28:1103-1112.

22 Bell DA, Liu Y, Cortopassi GA: Occurrence of bcl-2 oncogene translocation with increased frequency in the peripheral blood of heavy smokers. J Natl Cancer Inst 1995;87:223-224.

23 Roulland S, Lebailly P, Lecluse Y, Briand M, Pottier D, Gauduchon P: Characterization of the $\mathrm{t}(14 ; 18)$ BCL2-IGH translocation in farmers occupationally exposed to pesticides. Cancer Res 2004;64:2264-2269.

24 Quintanilla-Martinez L, Sander B, Chan JK, Xerri L, Ott G, Campo E, Swerdlow SH: Indolent lymphomas in the pediatric population: follicular lymphoma, IRF4/MUM1+ lymphoma, nodal marginal zone lymphoma and chronic lymphocytic leukemia. Virchows Arch 2016;468:141-157. 